\title{
Penerapan Metode Campuran Autoregressive Integrated Moving Average dan Quantile Regression (ARIMA-QR) untuk Peramalan Harga Cabai Sebagai Komoditas Strategis Pertanian Indonesia
}

\author{
Maria Cendanasari Kurniawan Putri dan Wiwik Anggraeni \\ Departemen Sistem Informasi, Fakultas Tekonologi Informasi dan Komunikaasi, Institut Teknologi \\ Sepuluh Nopember (ITS) \\ e-mail:wiwik@ is.its.ac.id
}

\begin{abstract}
Abstrak-Harga cabai sebagai komoditas pangan utama di Indonesia, dari tahun ke tahun terus mengalami fluktuasi, namun cenderung meningkat selama beberapa tahun terakhir. Hal ini mengharuskan pihak Disperindag untuk melakukan tindakan guna menjaga stabilisasi harga. Ketika pasokan cabai di pasar kurang, harganya dapat jauh melambung tinggi dari harga normal. Dan sebaliknya ketika pasokannya berlebihan, harganya akan turun jauh di bawah harga normal. Hal ini dipengaruhi oleh berbagai faktor seperti musim panen, jumlah pasokan, konsumsi masyarakat dan lain-lain. Oleh karena itu, diperlukan suatu metode peramalan untuk dapat
\end{abstract} memperkirakan harga dari komoditas strategis ini sehingga dapat digunakan untuk mendukung pembuatan keputusan terkait dengan masalah harga. Untuk itu, dalam penelitian ini dilakukan peramalan harga beras dengan menggunakan metode ARIMA-QR. Penggunaaan metode ARIMA adalah karena metode ini memiliki sifat yang fleksibel (mengikuti pola data), dan memiliki tingkat akurasi peramalan yang cukup tinggi. Sedangkan alasan penambahan metode $Q R$ adalah karena dalam studi ini melibatkan beberapa variabel yang berpengaruh dan agar dapat melihat secara lebih rinci pada setiap kuantil atau poin peramalan sehingga dibutuhkan analisis regresi yaitu quantile regression. Tujuan utama dari studi ini ialah untuk mengetahui harga cabai di periode berikutnya sehingga dapat membantu dalam pengambilan keputusan ataupun kebijakan terbaik yang perlu diterapkan terkait harga, sehingga dapat meningkatkan kesejahteraan masyarakat Indonesia. Dalam melakukan peramalan ini digunakan beberapa variabel yang berpengaruh terhadap fluktuasi harga cabai seperti produksi, konsumsi, luas panen, dan nilai peramalan harga beras yang telah dilakukan sebelumnya. Data yang digunakan adalah data bulanan mulai dari tahun 2000 hingga tahun 2016. Hasil evaluasi model menggunakan MAPE membuktikan bahwa metode yang dipilih baik ARIMA maupun ARIMA-QR memiliki tingkat akurasi yang tinggi, karena nilai MAPE masih di bawah 20\%. Adapun peramalan dengan menggunakan metode ARIMA-QR dengan melibatkan semua variabel pada studi kasus ini untuk keempat provinsi selain Jawa Barat adalah lebih baik jika dibandingkan metode ARIMA-QR tanpa variabel hari besar nasional. Jika dibandingkan dengan metode ARIMA, hasil peramalan ARIMA adalah lebih baik jika dibandingkan metode ARIMA-QR dengan quantile 0.25 dan 0.75. Sementara ARIMA-QR yang melibatkan seluruh variabel dengan quantile 0.50 (median) untuk keempat provinsi selain Jawa Barat memiliki nilai MAPE yang lebih baik dari metode ARIMA. Adapun bila hasil peramalan diukur dengan MDA, metode ARIMA menunjukkan hasil yang lebih baik daripada ARIMA-QR. Dengan kata lain, peramalan dengan metode ARIMA dapat lebih mengikuti pola data aktual dibandingkan metode ARIMA-QR.

Kata Kunci-Peramalan, komoditas strategis pertanian, harga cabai merah, ARIMA, Quantile regression, ARIMA$Q R$.

\section{PENDAHULUAN}

CALAH satu komoditas atau tanaman hortikultura yang memiliki nilai ekonomi penting di Indonesia ialah cabai (Capsicum Annum), karena buahnya selain dijadikan sayuran atau bumbu masak juga mempunyai kapasitas menaikkan pendapatan petani, sebagai bahan baku industri, memiliki peluang eks por, serta sebagai sumber vitamin C [1].

Cabai merupakan salah satu komoditi yang menjadi primadona pasar dan termasuk komoditi strategis di Indonesia. Dari sisi konsumsinya, cabai mempunyai pangsa yang cukup signifikan, tercermin dari bobot inflasinya. Pada tahun 2010, cabai merah merupakan tiga besar komoditas penyebab inflasi [2].

Berdasarkan data dari Badan Pusat Statistik (BPS), produksi cabai besar segar dengan tangkai tahun 2014 sebesar 1,075 juta ton. Apabila dibandingkan dengan tahun 2013, terjadi kenaikan produksi sebesar 61,73 ribu ton $(6,09 \%)$. Kenaikan ini disebabkan oleh kenaikan produktivitas sebesar 0,19 ton per hektar $(2,33 \%)$ dan peningkatan luas panen sebesar 4,62 ribu hektar (3,73\%) dibandingkan tahun 2013 [3]. Namun meskipun melimpahnya jumlah produksi, permintaan terhadap komoditi tersebut juga sangat tinggi. Berdasarkan data yang disampaikan oleh Menteri Dalam Negeri (Mendagri) RI Tjahjo Kumolo, jumlah penduduk Indonesia per 30 Agustus 2017 
sebanyak 261.142.385 jiwa [4]. Dengan jumlah penduduk yang sangat banyak tersebut, dapat dipastikan bahwa kebutuhan akan komoditas strategis pertanian akan sangat tinggi.

Berdasarkan fakta-fakta di atas, secara otomatis pasokan cabai dari pertanian tidak bisa stabil setiap saat sehingga harga cabai di pasaran pun cenderung tidak stabil dan sering mengalami lonjakan. Lonjakan harga cabai di atas $100 \%$ pun sudah sangat sering terjadi. Pada saat musim tertentu (musim hujan dan musim hajatan / perayaan hari besar agama), biasanya harga cabai meningkat tajam sehingga mempengaruhi tingkat inflasi [5]. Harga yang cenderung berfluktuasi menyebabkan resiko kerugian petani menjadi besar. Petani selaku produsen membutuhkan kepastian haga jual sebelum mereka memutuskan untuk menanam cabai atau tidak. Hal ini dilakukan untuk mengurangi resiko kerugian jatuhnya harga. Hal yang sama juga dialami oleh konsumen, khususnya konsumen industri. Mereka memerlukan kepastian harga cabai untuk mengendalikan biaya bahan baku mereka dalam proses produksi. Sementara para pedagang perantara menghadapi resiko kerugian akibat harga beli dan harga jual yang tidak pasti sehingga mereka juga membutuhkan kepastian harga untuk mengurangi resiko tersebut. Namun fluktuasi harga cabai merah (yang bahkan bisa terjadi dalam rentang waktu singkat) membuat kepastian harga tidak dapat diperoleh baik para petani, pedagang, maupun konsumen. Oleh karena itu, diperlukan suatu metode untuk dapat memperkirakan harga dari komoditas strategis ini sehingga dapat digunakan untuk pendukung pembuatan keputusan terkait dengan masalah harga.

Menurut [6], metode peramalan dari Box-Jenkins merupakan teknik uji linier yang istimewa yang mana sama sekali tidak menggunakan variabel independen, melainkan menggunakan nilai-nilai sekarang dan nilai-nilai lampau dari variabel dependen untuk menghasilkan peramalan jangka pendek yang akurat. Metode ini berbeda dengan metode peramalan lain karena metode ini tidak mensyaratkan suatu pola data tertentu supaya model dapat bekerja dengan baik. Sementara alasan penambahan metode $\mathrm{QR}$ adalah karena dalam studi ini melibatkan beberapa variabel yang berpengaruh dan agar dapat melihat secara lebih rinci pada setiap kuantil atau poin peramalan sehingga dibutuhkan analisis regresi yaitu quantile regression. Tujuan utama dari penelitian ini ialah untuk mengetahui harga beras di periode berikutnya sehingga dapat membantu dalam pengambilan keputusan ataupun kebijakan terbaik yang perlu diterapkan terkait harga, sehingga dapat meningkatkan kesejahteraan masyarakat Indonesia.

\section{DASAR TEORI}

\section{A. Peramalan}

Peramalan adalah proses memperkirakan nilai di masa mendatang dengan menggunakan data yang ada di masa lampau. Data di masa lampau secara sistematis dikombinasikan dan diolah untuk memperkirakan suatu nilai di masa mendatang. Terdapat dua pendekatan untuk melakukan peramalan, yaitu dengan pendekatan kualitatif dan pendekatan kuantitatif [7].

a. Metode peramalan kualitatif yang menggabungkan faktorfaktor seperti intuisi pengambilan keputusan, emosi, pengalaman pribadi

b. Metode peramalan kuantitatif yang menggunakan satu atau lebih model matematis dengan data masa lalu dan variabel sebab akibat untuk meramalkan permintaan. Pada dasarnya metode peramalan kuantitatif dibagi menjadi dua, yaitu model deret waktu (time series), dan model kausal.

Metode peramalan kuantitatif juga dapat dikelompokkan menjadi dua jenis, yaitu :

1) Model deret waktu/time series

Pada model ini, suatu variabel diramalkan berdasarkan nilai variabel itu sendiri di periode sebelumnya

2) Model kausal/explanatory

Pada model ini, suatu variabel diramalkan berdasarkan nilai dari satu atau lebih variabel lain yang berpengaruh. Atau dengan kata lain model kausal adalah memasukkan dan menguji variabel-variabel yang diduga akan mempengaruhi variabel dependen. Model ini biasanya menggunakan analisis regresi untuk menentukan mana variabel yang signifikan mempengaruhi variabel dependen. Selain menggunakan analisis regresi, model kausal juga dapat menggunakan metode ARIMA atau Box-Jenkins untuk mencari model terbaik yang dapat digunakan dalam peramalan

Secara umum, dalam melakukan peramalan terdiri dari beberapa tahapan khususnya jika menggunakan metode kuantitatif [8].Tahapan tersebut adalah:

a) Mendefinisikan tujuan dari peramalan

b) Membuatdiagram pencar (Plot Data)

c) Memilih model peramalan yang tepat sesuai dengan plot data

d) Melakukan peramalan

e) Menghitung kesalahan ramalan (forecast error)

f) Memilih metode peramalan dengan kesalahan yang terkecil

g) Melakukan verifikasi peramalan

Perhitungan nilai kesalahan peramalan untuk melihat tingkat akurasi peramalan dapat dilakukan dengan menggunakan MDA dan MAPE dengan persamaan berikut.

$$
\begin{aligned}
& \frac{1}{N} \sum 1 \operatorname{sign}\left(A_{t}-A_{t-1}\right)==\operatorname{sign}\left(F_{t}-F_{t-1}\right) \\
& M A P E=100\left(\frac{1}{n} \sum_{t=1}^{n}\left|\frac{y_{t}-\hat{y}_{t}}{y_{t}}\right|\right)
\end{aligned}
$$

\section{B. Box Jenkins (ARIMA)}

ARIMA (Autoregressive Integrated Moving Average) atau Model Box-Jenkins merupakan salah satu teknik model peramalan timeseries yang hanya berdasarkan perilaku data variabel yang diamati. ARIMA memiliki sifat yang fleksibel (mengikuti pola data), memiliki tingkat akurasi peramalan yang cukup tinggi. Mengikuti pola data disini maksudnya adalah jika data tidak stasioner, data tersebut dapat disesuaikan menjadi 
data stasioner dengan melakukan differencing. Adapun langkah-langkah yang harus diambil dalam menganalisis data dengan teknik Box-Jenkins atau ARIMA adalah sebagai berikut [8]:

Langkah 1. Identifikasi Model

Pada tahap ini, kita memilih model yang tepat yang bisa mewakili deret pengamatan. Identifikasi model dilakukan dengan:

a. Membuat plot data time series agar dapat diketahuiapakah data mengandung trend, musiman, outlier, variansi tidak konstan. Jika data time series tidak stasioner maka data harus distasionerkan terlebih dahulu. Jika data tidak stasioner dalam varians dan mean, maka langkah pertama harus menstabilkan variansinya.

b. Menghitung dan mencocokkan sampel ACF dan PACF dari data time series yang asli. Sampel ACF dan PACF dari data time series yang asli dapat digunakan untuk menentukan tingkat differencing yang sebaiknya digunakan.

c. Menghitung dan mencocokkan sampel ACF dan PACF dari data time series yang telah ditransformasikan dan didiferencing.

Langkah 2. Estimasi Parameter

Pada tahap ini, kita memilih taksiran model yang baik dengan melakukan uji hipotes is untuk parameter.

Hipotes is :

$$
\begin{aligned}
& H 0 \text { : parameter tidak signifikan } \\
& H 1: \text { parameter signifikan } \\
& \text { Level toleransi }(\alpha)=5 \%=0,05 \\
& \text { Kriteria uji : Tolak } H 0 \text { jika p-value }<\alpha .
\end{aligned}
$$

Langkah 3. Uji Diagnosis

Setelah mendapatkan estimator ARIMA, langkah selanjutnya adalah memilih model yang mampu menjelaskan data dengan baik. Caranya adalah dengan melihat apakah residual bersifat random sehingga merupakan residual yang relatif kecil. Jika tidak, maka harus kembali ke langkah pertama untuk memilih model yang lain.

Langkah 4. Prediksi (Peramalan)

Setelah didapatkan model terbaik yang sesuai, maka langkah selanjutnya adalah menggunakan model tersebut untuk melakukan peramalan.

\section{Regresi}

Regresi merupakan teknik statistika untuk menentukan persamaan garis atau kurva dengan meminimumkan penyimpangan antara data pengamatan dan nilai-nilai dugaannya [9]. Secara luas, analisis regresi diartikan sebagai suatu analisis ketergantungan antara variabel tergantung (independent variable) kepada variabel bebas (dependent variable). Analis is regresi diartikan sebagai analisis variabel bebas dalam rangka membuat estimasi atau prediksi dari nilai variabel tergantung dependent variable) dengan diketahuinya nilai variabel bebas [10].

\section{Quantile Regression}

Regresi kuantil sebagai suatu pendekatan dalam analisis regresi [11]. Regresi kuantil dapat dianggap sebagai perluasan dari model Ordinary Least Square. Secara khusus regresi OLS hanya memperkirakan bagaimana variabel prediktor terkalit dengan nilai rata-rata variabel respon, sedangkan regresi kuantil memungkinkan untuk model prediktor terhadap berbagai lokasi/pengukuran variabel respon [11].

\section{METODOLOGI}

\section{A. Sumber Data dan Variabel Penelitian}

Data yang digunakan dalam penelitian ini adalah data harga cabai, produksi, konsumsi, luas panen, hari besar nasional, dari tahun 2008-2016.

\section{B. Tahapan Penelitian}

Berikut adalah tahapan dalam penelitian yang dilakukan untuk peramalan ARIMA-QR:

1. Persiapan Data

a. Membagi data menjadi $70 \%$ training set dan $30 \%$ testing set

2. Peramalan menggunakan ARIMA

a. Identifikasi Model

Pada tahap identifikasi model dilakukan pembuatan plot data time series. Kemudian dilakukan uji stasioner ragam dan uji stasioner rataan. Jika data belum stasioner dalam ragam, maka perlu dilakukan proses transformasi. Jika data belum stasioner terhadap mean, maka dilakukan proses differencing. Identifikasi model ARIMA dapat dilakukan dengan menggunakan fungsi ACF maupun PACF dari data yang sudah stasioner untuk menentukan model awal (penentuan orde AR dan MA).

b. Estimasi Parameter

Parameter dikatakan signifikan jika memiliki nilai $\mathrm{p}$ value $<\alpha$ atau $p$-value $<0,05$. Jika telah menemukan parameter yang sesuai, maka dilanjutkan dengan proses uji diagnosa

c. Uji Diagnosa

Uji diagnosa dapat dilakukan dengan membuat plot ACF dan PACF untuk residualnya. Uji diagnosa dapat dilihat dari nilai $\mathrm{p}$ pada correlogram q-statistic dan squared residual. Nilai $\mathrm{p}>0,05$ pada q-statistic menandakan bahwa residual atau sisaan bersifat random atau acak, yang berarti model dapat diterima. Nilai $\mathrm{p}>0.05$ pada squared residual menandakan bahwa sisaan bersifat homogen. Model yang telah memnuhi kriteria dapat digunakan untuk melakukan peramalan.

d. Peramalan

Setelah mendapatkan model terbaik dari hasil uji parameter dan uji diagnosa, maka proses selanjutnya adalah melakukan peramalan dengan menggunakan model tersebut. Peramalan dilakukan 
untuk memperkirakan atau memprediksi harga beras hingga tahun 2018.

3. Peramalan menggunakan metode Quantile

Regression (QR)

a. Menentukan quantile

quantile yang digunakan dalam penelitian ini adalah $0.25,0.50$, dan 0.75 .

b. Menganalis is variabel

Menganalisis variabel yaitu terkait variabel independen dan regressor (variabel bebas), termasuk menganalis is hubungan antar variabel.

c. Mencari nilai prediksi

d. Menghitung kesalahan peramalan

4. Analaisa Hasil dan penarikan kesimpulan

Menganalisa dan membandingkan metode antara ARIMA saja dan metode campuran ARIMA-QR.

\section{ANALISIS DAN PEMBAHASAN}

\section{A. Pemodelan ARIMA}

Pada tahapan ini model yang telah dihasilkan dibandingkan dengan menggunakan data pelatihan (training) untuk menentukan model terbaik. Tabel 1 menunjukkan hasil pengukuran kinerja model dengan menggunakan nilai MAPE. Hasil uji coba model untuk data harga cabai terangkum pada Tabel III.1.

Tabel 1

Hasil Uji Coba Model Data Training Set Harga Cabai

\begin{tabular}{lcc}
\hline \hline \multicolumn{1}{c}{ Provinsi } & Model & MAPE \\
\hline Sumatera Barat & ARIMA $(1,0,12)$ & $9,801 \%$ \\
Jawa Barat & ARIMA $(1,1,1)$ & $9,243 \%$ \\
Jawa Timur & ARIMA $(0,1,1)$ & $3,961 \%$ \\
Jawa Tengah & ARIMA $(1,1,1)$ & $12,102 \%$ \\
Sulawesi Selatan & ARIMA $(3,1,0)$ & $6,236 \%$ \\
\hline \hline
\end{tabular}

Pada Tabel 1 didapatkan bahwa MAPE uji coba model data harga cabai untuk provinsi Jawa Tengah dapat dikatakan baik, sementara untuk MAPE di keempat provinsi lainnya $\leq 10 \%$ sehingga kemampuan peramalan dikatakan sangat baik. Hasil validasi model untuk data harga cabai di lima provinsi terangkum pada Tabel 2.

Tabel 2.

Hasil Validasi Model Data Testing Set Harga Cabai

\begin{tabular}{|l|c|c|c|}
\hline \multicolumn{1}{|c|}{ Provinsi } & Model & MAPE & $\begin{array}{c}\text { Kemampuan } \\
\text { Peramalan }\end{array}$ \\
\hline Sumatera Barat & $\operatorname{ARIMA}(1,0,12)$ & $1,970 \%$ & Sangat Baik \\
\hline Jawa Barat & $\operatorname{ARIMA}(1,1,1)$ & $6,632 \%$ & Sangat Baik \\
\hline Jawa Timur & $\operatorname{ARIMA}(0,1,1)$ & $14,426 \%$ & Baik \\
\hline Jawa Tengah & $\operatorname{ARIMA}(1,1,1)$ & $8,791 \%$ & Sangat Baik \\
\hline Sulawesi Selatan & $\operatorname{ARIMA}(3,1,0)$ & $10,853 \%$ & Baik \\
\hline
\end{tabular}

Dari Tabel 2 didapatkan seluruh provinsi kecuali Jawa Tengah memiliki nilai MAPE dengan kemampuan peramalan sangat baik dan nilai MAPE untuk data harga di Jawa Tengah emampuan peramalannya baik sehingga model dapat digunakan untuk peramalan periode selanjutnya. Hasil peramalan periode mendatang menggunakan ARIMA. Model terbaik ARIMA yang dipilih digunakan untuk melakukan peramalan hingga tahun 2018.

Adapun nilai rata-rata MAPE pada peramalan 5 provinsi adalah 7,327\% (sangat baik). Dengan kata lain, seluruh data harga di kelima provinsi rata-rata menunjukkan hasil MAPE dengan kemampuan peramalan sangat baik sehingga model dapat diterima dan digunakan untuk peramalan data.

\section{B. Permodelan Quantile Regression}

Model yang dipilih dalam metode quantile regression pada penelitian ini adalah mengacu pada teori Trimean, yaitu menggunakan quantile $0.25,0.5$, dan 0.75 .

Hubungan antar variabel dapat dihitung dengan uji korelasi melalui perhitungan regresi linier berganda. Adapun hasil perhitungan untuk uji korelasi secara manual dengan bantuan Microsoft Excel antara variabel hari besar terhadap harga ditunjukkan pada Tabel 3. Sementara dari Tabel III.4 didapatkan hasil bahwa dari kelima provinsi, hasil peramalan ARIMA memiliki pengaruh yang paling tinggi diantara variabel lain sedangkan variabel hari bes ar nasional merupakan variabel yang pengaruhnya sangat rendah / paling kecil.

Tabel 3.

Hubungan Variabel X terhadap Variabel Y

\begin{tabular}{|c|c|c|c|c|c|}
\hline \multirow{2}{*}{ Variabel X } & \multicolumn{5}{|c|}{ Variabel Y Harga Cabai di Masing-masing Provinsi } \\
\cline { 2 - 6 } & Sumatera Barat & Jawa Barat & Jawa Timur & Jawa Tengah & Sulawesi Selatan \\
\hline Hari Besar Nasional & 0.0250 & 0.0019 & 0.0390 & 0.0042 & -0.0483 \\
\hline Luas Panen & 0.4714 & 0.5033 & -0.4471 & 0.1793 & -0.2475 \\
\hline Produksi & 0.4462 & 0.5774 & 0.4878 & 0.4495 & 0.7189 \\
\hline Konsumsi & -0.2885 & -0.6040 & -0.5500 & -0.4815 & -0.6318 \\
\hline Peramalan ARIMA & 0.9701 & 0.9304 & 0.9520 & 0.9234 & 0.9585 \\
\hline
\end{tabular}

Tabel 4.

Keterangan Hubungan Variabel X terhadap Variabel Y

\begin{tabular}{|l|l|l|l|l|l|}
\hline \multirow{2}{*}{ Variabel X } & \multicolumn{5}{|c|}{ Variabel Y Harga Cabai di Masing-masing Provinsi } \\
\cline { 2 - 6 } & Sumatera Barat & Jawa Barat & Jawa Timur & Jawa Tengah & Sulawesi Selatan \\
\hline Hari Besar Nasional & Sangat Rendah & Sangat Rendah & Sangat Rendah & Sangat Rendah & Sangat Rendah \\
\hline Luas Panen & Cukup & Cukup & Sedang & Sangat Rendah & Sangat Rendah \\
\hline Produksi & Cukup & Cukup & Cukup & Cukup & Tinggi \\
\hline Konsumsi & Rendah & Tinggi & Sedang & Sedang & Tinggi \\
\hline Peramalan ARIMA & Sangat Tinggi & Sangat Tinggi & Sangat Tinggi & Sangat Tinggi & Sangat Tinggi \\
\hline
\end{tabular}

Adapun regresi OLS (Ordinary Least Square) dapat digunakan untuk memperkirakan bagaimana variabel prediktor atau variabel pengaruh terkait dengan nilai rata-rata variabel respon.

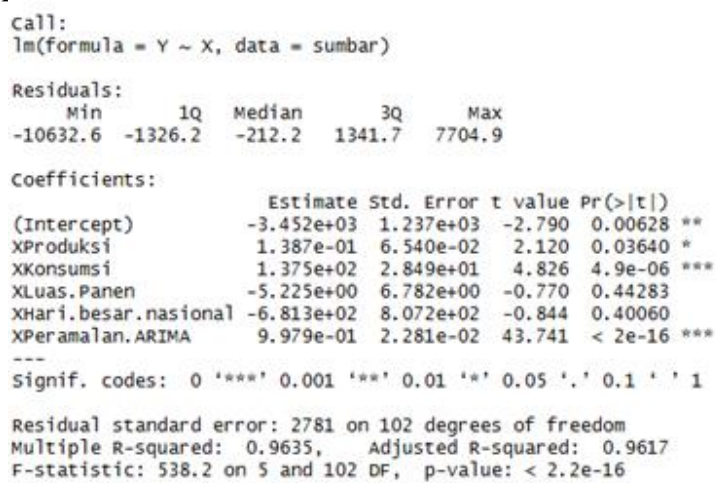

Gambar 1. Hasil Regresi OLS Data di Sumatera Barat 
Gambar 1 merupakan hasil dari regresi OLS yang menunjukkan bahwa variabel yang berpengaruh secara signifikan untuk data di Jawa Timur adalah variabel konsumsi dan hasil peramalan menggunakan metode ARIMA yang telah didapatkan sebelumnya. Tingkat signifikansi masing-masing variabel tersebut berbeda-beda. Untuk variabel hasil peramalan ARIMA dan juga konsumsi merupakan variabel yang berpengaruh terhadap harga cabai dalam level signifikansi (toleransi kesalahan / error) sebesar 0.001 atau dengan kata lain sebesar $99.9 \%$ variabel tersebut berpengaruh secara signifikan terhadap harga cabai. Sementara variabel produksi memiliki pengaruh secara signifikan pada level signifikansi sebesar 0.05. Kemudian untuk variabel lainnya, yakni produksi, luas panen, dan hari besar nasional tidak berpengaruh secara signifikan terhadap harga cabai.

\section{Perbandingan Metode}

Analisa hasil peramalan dilakukan untuk metode ARIMA, dan metode campuran ARIMA-QR. Untuk melihat perbandingan antara kedua metode tersebut, maka dilakukan perbandingan MAPE pada data aktual. Nilai MAPE yang lebih kecil menunjukkan bahwa metode tersebut dapat menghasilkan nilai peramalan yang lebih baik. Tabel 5 berikut ini menunjukkan hasil perbandingan MAPE antara metode ARIMA dan ARIMA-QR.

Tabel 5.

Perbandingan MAPE ARIMA dan ARIMA-QR

\begin{tabular}{|l|l|l|l|l|}
\hline Provinsi & \multirow{2}{*}{ ARIMA } & \multicolumn{3}{|l|}{ ARIMA QR-1 (semua variabel) } \\
\cline { 3 - 5 } & & Q1 & Q2 & Q3 \\
\hline Jawa Barat & $\mathbf{8 . 4 7 \%}$ & $10.30 \%$ & $9.45 \%$ & $13.46 \%$ \\
\hline Jawa Timur & $7.06 \%$ & $7.60 \%$ & $\mathbf{6 . 8 2} \%$ & $10.02 \%$ \\
\hline Jawa Tengah & $11.18 \%$ & $12.29 \%$ & $\mathbf{1 1 . 0 6} \%$ & $17.09 \%$ \\
\hline Sumatera Barat & $7.48 \%$ & $7.68 \%$ & $\mathbf{6 . 6 4} \%$ & $8.66 \%$ \\
\hline Sulawesi Selatan & $9.48 \%$ & $10.03 \%$ & $\mathbf{9 . 1 2} \%$ & $12.54 \%$ \\
\hline
\end{tabular}

Dari hasil keseluruhuan nilai MAPE di atas, dapat disimpulkan bahwa baik metode ARIMA, maupun ARIMA-QR dapat dikatakan baik untuk digunakan karena memiliki nilai MAPE di bawah $20 \%$. Jika diperinci setiap provinsi, peramalan ARIMA di keempat provinsi selain Jawa Tengah dapat dikatakan sangat baik karena nilai MAPE-nya kurang dari $10 \%$. Namun, jika dibandingkan dengan metode ARIMA-QR yang melibatkan semua variabel, untuk keempat provinsi selain Jawa Barat, terdapat nilai MAPE yang lebih rendah dari peramalan ARIMA, yakni pada quantile 0.50 atau median.

\section{KESIMPULAN DAN SARAN}

\section{A. Kesimpulan}

Berdasarkan hasil penelitian pada studi ini, maka didapatkan kesimpulan sebagai berikut:

1. Didapatkan model ARIMA terbaik untuk peramalan harga cabai di setiap provinsi. Hasil pemodelan ARIMA dikatakan baik, karena baik data training set, testing set, maupun keseluruhan memiliki nilai MAPE di bawah $20 \%$ untuk setiap provinsi.

2. Peramalan dengan menggunakan metode ARIMA-QR dengan melibatkan semua variabel pada studi kasus ini untuk keempat provinsi selain Jawa Barat adalah lebih baik jika dibandingkan dengan metode ARIMAQR tanpa variabel hari besar nasional.

3. Secara keseluruhan, hasil pemodelan ARIMA-QR ini dapat dikatakan baik, karena untuk setiap quantile di kelima provinsi memiliki nilai MAPE di bawah $20 \%$.

4. Peramalan dengan menggunakan metode ARIMA pada studi kasus ini untuk kelima provinsi adalah lebih baik jika dibandingkan metode ARIMA-QR dengan quantile 0.25 dan 0.75. Sementara ARIMA-QR yang melibatkan seluruh variabel dengan quantile 0.50 (median) untuk keempat provinsi selain Jawa Barat memiliki nilai MAPE yang lebih baik dari metode ARIMA. Adapun bila menggunakan pengukuran MDA di keempat provinsi selain Sulawesi Selatan, metode ARIMA menunjukkan hasil yang lebih baik daripada ARIMA-QR. Dengan kata lain, peramalan dengan metode ARIMA dapat lebih mengikuti pola data aktual dibandingkan metode ARIMA-QR.

\section{Saran}

Berdasarkan hasil penelitian pada studi ini, maka saran untuk penelitian selanjutnya adalah sebagai berikut:

1. Hasil penelitian (model ARIMA yang ditemukan) dapat dioptimalkan dengan menggunakan metode lanjutan lainnya.

2. Perlu adanya penelitian dan analis is lebih lanjut terkait variabel-variabel lain yang mungkin memiliki pengaruh terhadap peningkatan harga cabai.

3. Untuk variabel hari besar nasional yang digunakan pada penelitian ini hanya terbatas pada hari raya Idul Fitri dan Natal saja, oleh karenanya tidak banyak berpengaruh terhadap harga cabai. Untuk penelitian selanjutnya, dapat mengembangkan variabel ini untuk data hari-hari besar nasional lainnya sehingga dapat lebih terlihat bagaimana pengaruhnya terhadap harga.

\section{UCAPAN TERIMA KASIH}

Penulis mengucapkan terima kasih kepada pihak Perum BPS sebagai sumber data, inspirasi, dan studi kasus dalam penelitian.

\section{DAFTAR PUSTAKA}

LIPTAN LPTP Koya Barat, "Budidaya Tanaman Cabe Lembar Informasi Pertanian,” 2017.

Pusat Data dan Sistem Informasi Pertanian Sekretariat Jenderal Kementerian Pertanian, “Outlook Cabai 2016," 2016. [Online].

Available: http://epublikasi.setjen.pertanian.go.id/epublikasi/outlook/2016/ Hortikultura/OUTLOOK

,CABAI ,2016/files/assets/common/downloads/OUTLOOK ,CABAI ,2016.pdf.

Badan Pusat Statistik, "Badan Pusat Statistik," 2015. [Online]. Available: https://www.bps.go.id/brs/view/id/1168.

Kementrian Dalam Negeri, "Mendagri Lebih 175 Juta WNI 
Telah Merekam Data Kependudukan,” 2017.

[5] E. L. Saptana et al., "Pengembangan model kelembagaan kemitraan usaha yang berdaya saing di kawasan sentra produksi hortikultura," Bogor, 2005.

[6] S. Assauri, Teknik dan Metode Peramalan. Jakarta: Fakultas Ekonomi UI, 1984.

[7] J. Heizer and B. Render, Operation Management, 7th ed. New Jersey: Prentice Hal, Inc, 2005.

[8] A. A. Juan and C. Serrat, Time Series Analysis C5 Arima (BoxJenkins) Models. 2007.
[9] R. Rahmawati, W. Widiarti, and P. Novianti, "Regresi Kuantil (Studi Kasus Padadata Suhu Harian)," in Prosiding Seminar Nasional Statistika Universitas Diponegoro, 2011.

[10] A. T. Basuki and N. Prawoto, Analisis Regresi dalam Penelitian Ekonomi \& Bisnis. Jakarta: PT Raja Grafindo Persada, 2016.

[11] I. Z. Ika Septiana Windi Antari, Wahyu, and Wibowo, "Pemodelan Indeks Prestasi Kumulatif Tahap Persiapan Mahasiswa IT S Jalur Seleksi Nasional Masuk Perguruan Tinggi Negeri Menggunakan Pendekatan," POMMITS, pp. 1-7. 